\title{
LETTER
}

\section{Cytokine profiles of suction pulmonary secretions from children infected with pandemic influenza $\mathrm{A}(\mathrm{H} 1 \mathrm{~N} 1) 2009$}

\author{
Hisashi Kawashima*, Soken Go, Yasuyo Kashiwagi, Yasuyuki Morishima, Taro Miura, Masanobu Ushio, Shigeo Nishimata \\ and Kouji Takekuma
}

See related research by Bermejo-Martin et al., http://ccforum.com/content/13/6/R201

Uncomplicated influenza in humans is characterized by massive virus replication in respiratory epithelial cells, inflammation and an abrupt onset. The novel influenza A (H1N1) 2009 caused an epidemic of critical illness and some patients rapidly developed severe acute respiratory distress syndrome [1,2]. Van Reeth [3] reviewed growing evidence that the so-called early cytokines produced at the site of infection mediate many of the clinical and pathological manifestations of influenza infection. Of those cytokines, Bermejo-Martin and colleagues [4] reported in Critical Care that T-helper 1 (Th1) and Th17 hypercytokinemia plays an important role as an early host response in severe pandemic influenza. Evaluating the differences in early immune responses between hospitalized patients with severe pandemic influenza and those with mild disease, high systemic levels of IFN- $\gamma$ and a group of mediators involved in the development of the Th17 (IL-8, IL-9, IL-17, IL-6) and Th1 (TNF- $\alpha$, IL-15, IL-12p70) responses were found exclusively in hospitalized patients. A significant inverse association was found between IL- 6 and IL- 8 and $\mathrm{PaO}_{2}$ in critical patients. They concluded that severe disease with respiratory involvement is characterized by early secretion of Th17 and Th1 cytokines.

We experienced two cases of pandemic influenza A(H1N1) 2009-associated pneumonia and encephalopathy, which were treated under mechanical ventilation. Cytokine analysis of their pulmonary secretions revealed different patterns from previous results (Figure 1). One patient showed no improvement with usual ventilation and had mediastinal emphysema and serious hypooxygenation; thus, the patient needed to be ventilated

*Correspondence: hisashi@tokyo-med.ac.jp

Department of Pediatrics, Tokyo Medical University, 6-7-1 Nishishinjuku, Shinjukuku, Tokyo160-0023, Japan using the special respiratory airway pressure release ventilation mode because of progression and the need for high pressure control. The second case with encephalopathy complicated with pneumonia underwent combined treatments of steroids and hypothermia because of intractable recurrent seizures. Their cytokine levels were extremely high, although serum 17 cytokines were within normal ranges. Cytokines in pulmonary secretions at first revealed high levels of IL-8, monocyte chemotactic protein (MCP)-1 and macrophage inflammatory protein1b (MIP-1b). On the other hand, IL-1b, 2, 4, 5, 6, 7, 10, $12,13,17, \mathrm{G}-\mathrm{CSF}, \mathrm{GM}-\mathrm{CSF}, \mathrm{IFN}-\gamma$ and TNF- $\alpha$ were normal or slightly increased. On 5th days after hospitalization other cytokines (IL-1 $\beta, 6,10,17$, G-CSF, GM-CSF, IFN- $\gamma$, MCP- 1 and TNF- $\alpha$ ) increased markedly in both cases. Given these findings, we suspect that

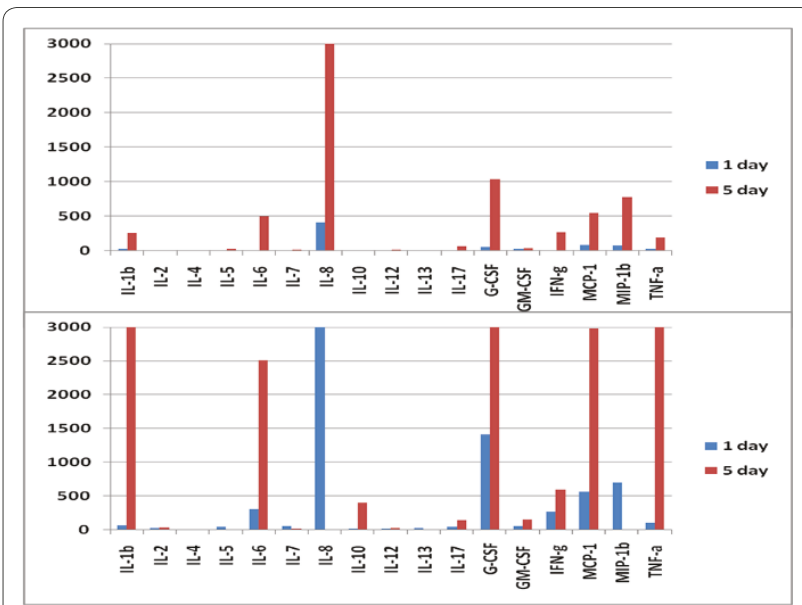

Figure 1. Cytokines in the pulmonary secretions of a case with serious distress and oxygenic disturbance (upper panel). Another case showed almost similar patterns (lower panel). G-CSF, granulocyte colony stimulating factor; GM-CSF, granulocytemacrophage colony stimulating factor; IFN, interferon; IL, interleukin; MCP, monocyte chemotactic protein; TNF, tumor necrosis factor. 
chemokines play a role mostly in lung injury associated with influenza $\mathrm{A}(\mathrm{H} 1 \mathrm{~N} 1) 2009$ infection in the early phase. High levels of chemokines and subsequent epithelial changes will increase the permeability in alveoli and fibrin leakage into interstitial tissue, followed by the consequent production of other inflammatory cytokines. Alternatively, we assume that secondary bacterial infections, which have been reported [5], influence the production of those cytokines (IL-6, IL-1b and TNF- $\alpha$ ).

\section{Authors' response}

Ignacio Martín-Loeches, Paula Ramirez, Jordi Rello, Raul Ortiz de Lejarazu, David Kelvin and Jesus F Bermejo-Martin

In a viral infection with a short period of incubation and a limited clinical course, the early immune response to the virus should be key to determining further clinical evolution. Work from our group was the first to report the early elevation of chemokines and Th1 and Th17 cytokines in severe pH1N1 infected adults [4]. More recently, To and colleagues [6] showed similar results, also in adults. Kawashima and colleagues now report elevated levels of chemokines and cytokines in lung secretions of two critically ill children with pH1N1 infection. These authors found chemokine and cytokine patterns very similar to those we found in adults, differing slightly in the timing that elevation occurs. In this sense, a major drawback for comparison of sequential profiling of cytokines between studies is how differences in defining the onset of symptoms is determined. In addition, our study was conducted with 35 patients and
15 controls, while Kawashima and colleagues' study was conducted with two children and no controls. Moreover, we examined plasma, while Kawashima examined lung secretions. Nevertheless, the findings from all three groups raise important fundamental questions. For example, are high cytokine and chemokine levels detrimental or beneficial to outcome? Furthermore, are there differences between children and adults? Also important is the contribution of mechanical ventilation in driving cytokine levels and contributing to secondary infections. Previous studies on severe respiratory viral infections have utilized several robust techniques for monitoring longitudinal changes in host immunity $[7,8]$. These previous studies, along with those currently coming from our group, from To and colleagues and Kawashima and colleagues indicate that cytokine and chemokine levels may be useful prognostic markers of pH1N1 disease.

\section{Abbreviations}

G-CSF, granulocyte colony stimulating factor; GM-CSF, granulocytemacrophage colony stimulating factor; IFN, interferon; IL, interleukin; MCP, monocyte chemotactic protein; Th, T-helper, TNF, tumor necrosis factor.

\section{Competing interests}

The authors declare that they have no competing interests.

\section{Acknowledgements}

Written consent for publication was obtained from the patients' relatives. The study group of Martín-Loeches et al. is supported by the Ministry of Science of Spain and "Consejería de Sanidad Junta de Castilla y León", projects GR09/0021, PI081236 and EMER07/050. CIHR, NIH and LKSF-Canada support DJK.

Published: 13 April 2010

\section{References}

1. Australia and New Zealand Extracorporeal Membrane Oxygenation (ANZ ECMO) Influenza Investigators, Davies A, Jones D, Bailey M, Beca J, Bellomo R, Blackwell N, Forrest P, Gattas D, Granger E, Herkes R, Jackson A, McGuinness S, Nair P, Pellegrino V, Pettilä V, Plunkett B, Pye R, Torzillo P, Webb S, Wilson M, Ziegenfuss M: Extracorporeal membrane oxygenation for 2009 influenza A(H1N1) acute respiratory distress syndrome. JAMA 2009, 302:1888-1895.

2. Mauad T, Hajjar LA, Callegari GD, da Silva LF, Schout D, Galas FR, Alves VA, Malheiros DM, Auler JO Jr, Ferreira AF, Borsato MR, Bezerra SM, Gutierrez PS, Caldini ET, Pasqualucci CA, Dolhnikoff M, Saldiva PH: Lung pathology in fatal novel human influenza A (H1N1) infection. Am J Respir Crit Care Med 2010, 181:72-79.

3. Van Reeth K: Cytokines in the pathogenesis of influenza. Vet Microbio/ 2000, 74:109-116.

4. Bermejo-Martin JF, Ortiz de Lejarazu R, Pumarola T, Rello J, Almansa R, Ramírez P, Martin-Loeches I, Varillas D, Gallegos MC, Serón C, Micheloud D, Gomez JM,
Tenorio-Abreu A, Ramos MJ, Molina ML, Huidobro S, Sanchez E, Gordón M, Fernández V, Del Castillo A, Marcos MA, Villanueva B, López CJ, RodríguezDomínguez M, Galan JC, Cantón R, Lietor A, Rojo S, Eiros JM, Hinojosa C, et al.: Th1 and Th17 hypercytokinemia as early host response signature in severe pandemic influenza. Crit Care 2009, 13:R201

5. Centers for Disease Control and Prevention (CDC): Bacterial coinfections in lung tissue specimens from fatal cases of 2009 pandemic influenza $A$ (H1N1) - United States, May-August 2009. WR Morb Mortal Wkly Rep 2009, 58:1071-1074

6. To KK, Hung IF, Li IW, Lee KL, Koo CK, Yan WW, Liu R, Ho KY, Chu KH, Watt CL, Luk WK, Lai KY, Chow FL, MokT, Buckley T, Chan JF, Wong SS, Zheng B, Chen H, Lau CC, Tse H, Cheng VC, Chan KH, Yuen KY: Delayed clearance of viral load and marked cytokine activation in severe cases of pandemic $\mathrm{H} 1 \mathrm{~N} 1$ 2009 influenza virus infection. Clin Infect Dis 2010, 50:850-859.

7. Cameron MJ, Ran L, Xu L, Danesh A, Bermejo-Martin JF, Cameron CM, Muller MP, Gold WL, Richardson SE, Poutanen SM, Willey BM, DeVries ME, Fang Y, Seneviratne C, Bosinger SE, Persad D, Wilkinson P, Greller LD, Somogyi R, Humar A, Keshavjee S, Louie M, Loeb MB, Brunton J, McGeer AJ; Canadian SARS Research Network, Kelvin DJ: Interferon-mediated immunopathological events are associated with atypical innate and adaptive immune responses in patients with severe acute respiratory syndrome. J Viro/ 2007, 81:8692-8706.

8. Bermejo-Martin JF, Garcia-Arevalo MC, Alonso A, De Lejarazu RO, Pino M, Resino S, Tenorio A, Bernardo D, Leon AJ, Garrote JA, Ardura J, Dominguez-Gil M, Eiros JM, Blanco-Quiros A, Munoz-Fernandez MA, Kelvin DJ, Arranz E: Persistence of proinflammatory response after severe respiratory syncytial virus disease in children. J Allergy Clin Immunol 2007, 119:1547-1550.

doi:10.1186/cc8918

Cite this article as: Kawashima $\mathrm{H}$, et al:: Cytokine profiles of suction pulmonary secretions from children infected with pandemic influenza $\mathrm{A}(\mathrm{H} 1 \mathrm{N1})$ 2009. Critical Care 2010, 14:411. 